\title{
An Empirical Approach to Modeling the Term Structure of the Japanese Government Bond Yields
}

\author{
Chikashi Tsuji ${ }^{1}$ \\ ${ }^{1}$ Professor, Faculty of Economics, Chuo University, Japan \\ Correspondence: Chikashi Tsuji, Faculty of Economics, Chuo University, 742-1 Higashinakano Hachioji-shi, \\ Tokyo 192-0393, Japan. Tel: 81-42-674-2211. E-mail: mail_sec_low@minos.ocn.ne.jp
}

Received: February 19, 2015 Accepted: March 5, 2015 Online Published: May 31, 2015

doi:10.5539/jms.v5n2p24 URL: http://dx.doi.org/10.5539/jms.v5n2p24

\begin{abstract}
This paper aims to empirically model the term structure of the Japanese government bond (JGB) yields. Specifically, we use bivariate-vector error correction models (VECMs) and attempt to capture the relations between various shorter-term and longer-term JGB yields. The interesting findings derived from our investigations by applying VECMs are as follows. 1) First, we find that the linkage between longer-term JGB yields and shorter-term JGB yields is effectively captured by the cointegrating equations (CEs) in the VECMs. 2) Second, we also reveal that, in general, the CEs in the VECMs for the JGBs' term structure statistically significantly explain the next month's time-series changes of the longer-term JGB yields.
\end{abstract}

Keywords: cointegration, JGB, term structure, VECM

\section{Introduction}

Term structure of interest rates is one of the appealing and interesting research topics in the fields of economics and finance because it includes rich information as to the economy and financial markets. However, it seems to be difficult for modeling the dynamic evolution of the term structure of interest rates effectively; one theory cannot always explain its shape and the relations among various yields of different maturities. There are many kinds of approaches to modeling the term structure of interest rates (e.g., Vasicek, 1977; Cox et al., 1985; Hull and White, 1990; Heath et al., 1992); however, the time-series characteristics and the adaptive theory of term structure tend to largely shift in accordance with the changes of economic environment, thus employing empirical approach is considered to be very natural for modeling the term structure.

Based on the above background and motivation, this paper aims to empirically model the term structure of various Japanese government bond (JGB) yields. More specifically, using bivariate-vector error correction models (VECMs), we attempt to capture the various relations between shorter-term and longer-term JGB yields. The interesting findings derived from our investigations by applying VECMs are as follows. 1) First, we find that the linkage between longer-term JGB yields and shorter-term JGB yields is effectively captured by the cointegrating equations (CEs) in VECMs. 2) Second, we also reveal that, in general, the CEs in the VECMs for the JGBs' term structure statistically significantly explain the next month's time-series changes of the longer-term JGB yields. As to the organization of this paper, the next section reviews the recent related studies, Section 3 documents our data and variables, Section 4 explains our models, Section 5 describes the estimation results of our VECMs, and Section 6 concludes the paper.

\section{Literature Review}

This section briefly conducts a literature review by focusing only on the recent related studies, which investigated the term structure of interest rates. First, using the UK data from 1993 to 2008, Chadha and Waters (2014) estimated a macro-finance yield curve model for both nominal and real forward yield curves. An interesting study of Hamilton and $\mathrm{Wu}$ (2014) investigated a number of testable implications of affine term structure models. Further, Dang-Nguyen et al. (2014) suggested that the affine dynamic Nelson-Siegel model (Nelson and Siegel, 1987) linked the affine class of models with the Nelson-Siegel interpolation scheme of yield curves, and they proposed an extended term structure model.

Moreover, Paccagnini (2015) studied the relationship between the US term structure of interest rates and the macroeconomic variables during the period of the Great Moderation. In addition, using data of the US, UK, and 
Germany, Jotikasthira et al. (2015) found that the US yield level and inflation together explained over two-thirds of the various maturity yields' covariances. Further, Kung (2015) studied the equilibrium term structure of nominal and real interest rates. This study also investigated the time-varying bond risk premiums implied by a stochastic endogenous growth model with monetary policy shocks and imperfect price adjustments. Furthermore, Kung (2015) showed that when calibrated to macroeconomic data, the proposed model by this study quantitatively well explained the means and volatilities of nominal bond yields; this study also pointed out the failure of the expectations hypothesis in their analyses.

Table 1. Descriptive statistics of the Japanese government bond yields: For the period from January 1984 to December 2014

\begin{tabular}{lllll}
\hline & J6M & J1Y & J2Y & J3Y \\
\hline Mean & 1.9117 & 1.9302 & 2.0093 & 2.1428 \\
Median & 0.4126 & 0.4936 & 0.6741 & 0.8961 \\
Maximum & 8.5243 & 8.5011 & 8.4701 & 8.4194 \\
Minimum & -0.0519 & -0.0169 & -0.0329 & -0.0116 \\
Std. Dev. & 2.4664 & 2.4233 & 2.3669 & 2.3440 \\
Skewness & 1.0553 & 1.0187 & 0.9689 & 0.9307 \\
Kurtosis & 2.6313 & 2.5426 & 2.4524 & 2.4016 \\
Observations & 372 & 372 & 372 & 372 \\
\hline & $\mathrm{J} 5 \mathrm{Y}$ & $\mathrm{J} 7 \mathrm{Y}$ & 3.0018 \\
\hline Mean & 2.4355 & 2.7065 & & 1.8565 \\
Median & 1.2111 & 1.5621 & & 8.3044 \\
Maximum & 8.2276 & 8.1088 & & 0.3266 \\
Minimum & 0.0167 & 0.1008 & & 2.1198 \\
Std. Dev. & 2.2786 & 2.2290 & & 0.6974 \\
Skewness & 0.7944 & 0.7180 & & 2.1117 \\
Kurtosis & 2.1946 & 2.0895 & & 372 \\
Observations & 372 & 372 & & \\
\hline
\end{tabular}

Notes: This table presents the descriptive statistics of the variables used in this study. 'Std. Dev.' denotes the value of standard deviation. In this table, J6M denotes the six-month Japanese government bond (JGB) yield; J1Y means the one-year JGB yield; J2Y denotes the two-year JGB yield; J3Y is the three-year JGB yield; J5Y denotes the five-year JGB yield; J7Y means the seven-year JGB yield; J10Y denotes the ten-year JGB yield. Our samples are monthly and the sample period spans January 1984 to December 2014.

\section{Data}

This section describes the data and notations of seven kinds of JGB yields used in this study. First, J6M denotes the six-month JGB yield, J1Y means the one-year JGB yield, and J2Y denotes the two-year JGB yield. Moreover, J3Y denotes the three-year JGB yield, J5Y means the five-year JGB yield, J7Y denotes the seven-year JGB yield, and J10Y means the ten-year JGB yield. Our samples are monthly and the full sample period in this study spans January 1984 to December 2014. All data are supplied by the QUICK Corp.

The time-series evolution of the above seven kinds of JGB yields is shown in Figure 1. In addition, the descriptive statistics of the above variables are displayed in Table 1. As Figure 1 shows, the seven JGB yields once increased around 1990, which is the period of the bubble economy in Japan, and then continuously decreased until the end of our sample period, December 2014. Moreover, from Table 1, we understand the following characteristics as to our seven kinds of JGB yields. 1) First, the mean values of the JGB yields become higher as their maturities are longer although this tendency is natural. 2) Second, very interestingly, volatility becomes lower as their maturities are longer. 3) Third, all skewness values are larger than zero and fourth, 4) all kurtosis values are lower than three, which is the value of the normal distribution. 


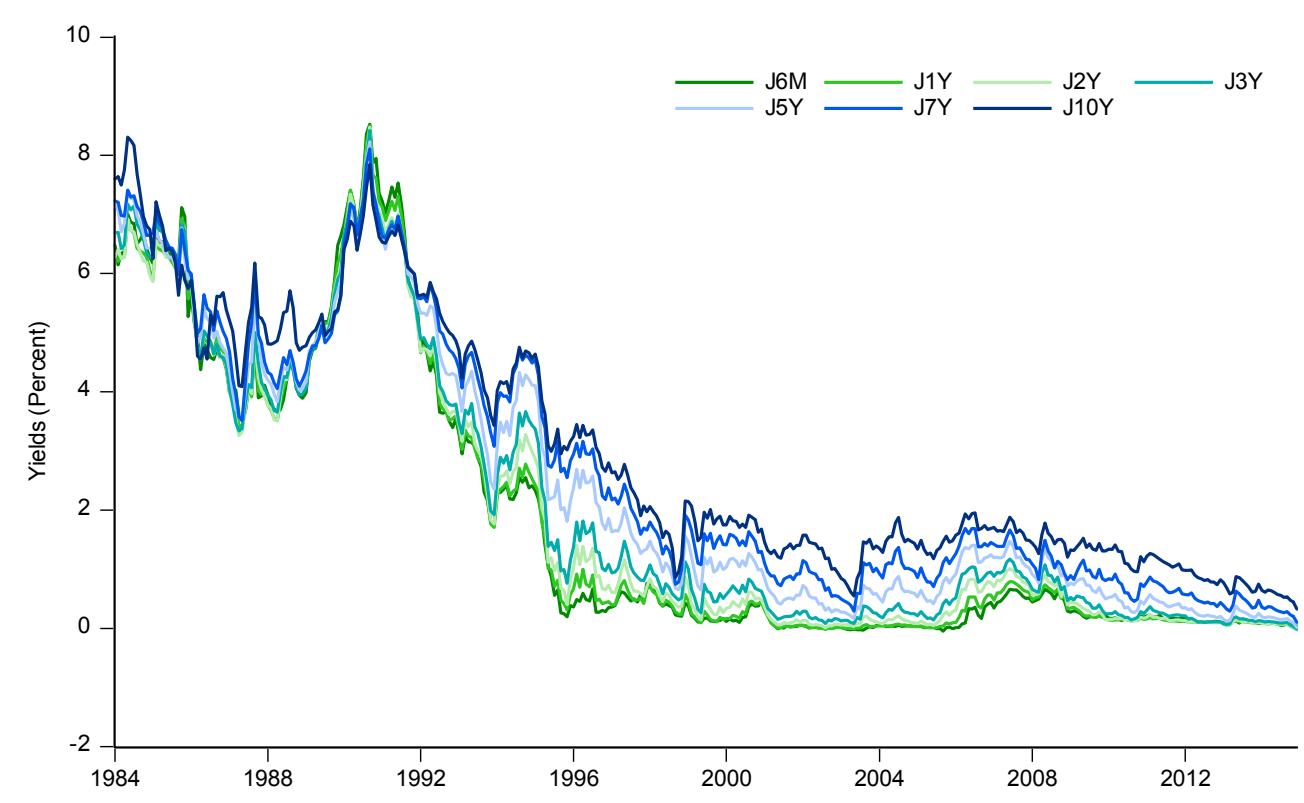

Figure 1. Time-series evolution of the term structure of the JGB in Japan

\section{Models}

In order to model the term structure of JGBs, we estimate six kinds of VECMs. Namely, they are models of 1) $\mathrm{J} 1 \mathrm{Y}$ and J6M; 2) J2Y and J6M; 3) J3Y and J6M; 4) J10Y and J6M; 5) J10Y and J5Y; 6) J10Y and J7Y. The model determinations are based on the Johansen's $(1991 ; 1995)$ cointegration tests and all our bivariate models are summarized as the following equations (1) and (2):

$$
\begin{aligned}
& \Delta J G B L_{t}=\kappa_{1} C E+\sum_{m=1}^{p} \xi_{1, m} \Delta J G B L_{t-m}+\sum_{n=1}^{q} \phi_{1, n} \Delta J G B S_{t-n}+\eta_{1, t}, \\
& \Delta J G B S_{t}=\kappa_{2} C E+\sum_{j=1}^{p} \xi_{2, j} \Delta J G B L_{t-j}+\sum_{k=1}^{q} \phi_{2, k} \Delta J G B S_{t-k}+\eta_{2, t} .
\end{aligned}
$$

In the above equations, $C E=J G B L_{t-1}+\lambda J G B S_{t-1}$ for the model of 1) J3Y and J6M whilst $C E=J G B L_{t-1}+$ $\lambda J G B S_{t-1}+v$ for the models of 1) J1Y and J6M; 2) J2Y and J6M; 3) J10Y and J6M; 4) J10Y and J5Y; 5) J10Y and J7Y. Lag orders $p$ and $q$ are different according to models. Further, in the above equations (1) and (2), JGBS denotes the shorter-term JGB yield whilst JGBL means the longer-term JGB yield. Moreover, $\triangle \mathrm{JGBS}$ denotes the first difference of the shorter-term JGB yield while $\triangle \mathrm{JGBL}$ means the first difference of the longer-term JGB yield.

\section{Estimation Results}

Estimation results of our six kinds of VECMs are shown in Table 2. More specifically, in Table 2, Panel A shows the results of J1Y and J6M, Panel B exhibits the results of J2Y and J6M, Panel C displays the results of J3Y and J6M, Panel D shows the results of J10Y and J6M, Panel E exhibits the results of J10Y and J5Y, and Panel F shows the results of J10Y and J7Y.

Our estimation results are very systematic and interesting because all coefficients $\lambda$ s are statistically significant with negative signs in all six models. In addition, CEs in VECMs are mostly statistically significant with negative signs in the equations that explain the changes of longer-maturity JGBs. Specifically, in Table 2, the CEs are statistically significant for explaining the variables of $\triangle \mathrm{J} 2 \mathrm{Y}$ (Panel B), $\Delta \mathrm{J} 3 \mathrm{Y}$ (Panel C), $\Delta \mathrm{J} 10 \mathrm{Y}$ (Panel D), $\triangle \mathrm{J} 10 \mathrm{Y}$ (Panel E), and $\triangle \mathrm{J} 10 \mathrm{Y}$ (Panel F). Moreover, the time-series evolution of the CEs derived from the VECMs is shown in Figure 2. In Figure 2, Panel A shows the time-series of the CE for J1Y and J6M, Panel B exhibits the time-series of the CE for J2Y and J6M, Panel C displays that of the CE for J3Y and J6M, Panel D shows the CE for J10Y and J6M, Panel E exhibits the CE for J10Y and J5Y, and Panel F shows the CE for J10Y and J7Y. From the above estimation results, we understand that the positive deviations of the longer-term JGB yields from the shorter-term JGB yields are negatively related to the one-month-ahead changes of the longer-term JGB yields. 
Table 2. Estimation results of the VECMs for the term structure of the JGB in Japan

\begin{tabular}{|c|c|c|c|c|c|}
\hline \multirow{2}{*}{$\begin{array}{l}\text { Panel A. J1Y and J6M } \\
\text { Cointegrating equation }\end{array}$} & & & \multicolumn{3}{|c|}{ Panel B. J2Y and J6M } \\
\hline & & & \multicolumn{3}{|c|}{ Cointegrating equation } \\
\hline & \multicolumn{2}{|l|}{ Coefficients } & & Coefficients & \\
\hline $\mathrm{J} 1 \mathrm{Y}(-1)$ & 1.0000 & & $\mathrm{~J} 2 \mathrm{Y}(-1)$ & 1.0000 & \\
\hline $\mathrm{J} 6 \mathrm{M}(-1)$ & $-0.9821 * * *$ & & $\mathrm{~J} 6 \mathrm{M}(-1)$ & $-0.9523 * * *$ & \\
\hline$p$-value & 0.0000 & & $p$-value & 0.0000 & \\
\hline Intercept & $-0.0500^{* * *}$ & & Intercept & $-0.1724 * * *$ & \\
\hline$p$-value & 0.0093 & & $p$-value & 0.0002 & \\
\hline \multirow[t]{4}{*}{ Error corrections } & & & \multicolumn{3}{|c|}{ Error corrections } \\
\hline & \multicolumn{2}{|l|}{ Variables } & & \multicolumn{2}{|l|}{ Variables } \\
\hline & $\Delta \mathrm{J} 1 \mathrm{Y}$ & $\Delta \mathrm{J} 6 \mathrm{M}$ & & $\Delta \mathrm{J} 2 \mathrm{Y}$ & $\Delta \mathrm{J} 6 \mathrm{M}$ \\
\hline & Coefficients & Coefficients & & Coefficients & Coefficients \\
\hline $\mathrm{CE}$ & -0.1161 & 0.1110 & $\mathrm{CE}$ & $-0.1674 * * *$ & -0.0056 \\
\hline$p$-value & 0.3194 & 0.3631 & $p$-value & 0.0030 & 0.9215 \\
\hline$\Delta \mathrm{J} 1 \mathrm{Y}(-1)$ & 0.0788 & 0.2018 & $\Delta \mathrm{J} 2 \mathrm{Y}(-1)$ & 0.0784 & $0.1812 *$ \\
\hline$p$-value & 0.6300 & 0.2388 & $p$-value & 0.3982 & 0.0547 \\
\hline$\Delta \mathrm{J} 6 \mathrm{M}(-1)$ & 0.0164 & -0.1190 & $\Delta \mathrm{J} 6 \mathrm{M}(-1)$ & 0.0571 & -0.0924 \\
\hline$p$-value & 0.9169 & 0.4688 & $p$-value & 0.5392 & 0.3280 \\
\hline $\operatorname{Adj} . R^{2}$ & 0.0002 & 0.0010 & $\operatorname{Adj} . R^{2}$ & 0.0316 & 0.0025 \\
\hline \multicolumn{3}{|l|}{ Panel C. J3Y and J6M } & \multicolumn{3}{|c|}{ Panel D. J10Y and J6M } \\
\hline \multicolumn{3}{|l|}{ Cointegrating equation } & \multicolumn{3}{|c|}{ Cointegrating equation } \\
\hline & \multicolumn{2}{|l|}{ Coefficients } & & \multicolumn{2}{|l|}{ Coefficients } \\
\hline $\mathrm{J} 3 \mathrm{Y}(-1)$ & 1.0000 & & $\mathrm{~J} 10 \mathrm{Y}(-1)$ & 1.0000 & \\
\hline $\mathrm{J} 6 \mathrm{M}(-1)$ & \multicolumn{2}{|l|}{$-0.9653 * * *$} & $\mathrm{~J} 6 \mathrm{M}(-1)$ & $-0.8925 * * *$ & \\
\hline \multirow[t]{3}{*}{$p$-value } & \multirow{3}{*}{\multicolumn{2}{|c|}{0.0000}} & $p$-value & 0.0000 & \\
\hline & & & Intercept & $-1.0881 * * *$ & \\
\hline & & & $p$-value & 0.0000 & \\
\hline \multicolumn{3}{|l|}{ Error corrections } & \multicolumn{3}{|c|}{ Error corrections } \\
\hline & Variables & & & Variables & \\
\hline & $\Delta \mathrm{J} 3 \mathrm{Y}$ & $\Delta \mathrm{J} 6 \mathrm{M}$ & & $\Delta \mathrm{J} 10 \mathrm{Y}$ & $\Delta \mathrm{J} 6 \mathrm{M}$ \\
\hline & Coefficients & Coefficients & & Coefficients & Coefficients \\
\hline $\mathrm{CE}$ & $-0.0771^{* * *}$ & -0.0288 & $\mathrm{CE}$ & $-0.0423 * *$ & 0.0229 \\
\hline$p$-value & 0.0048 & 0.2816 & $p$-value & 0.0276 & 0.2172 \\
\hline$\Delta \mathrm{J} 3 \mathrm{Y}(-1)$ & 0.0759 & $0.2033 * *$ & $\Delta \mathrm{J} 10 \mathrm{Y}(-1)$ & -0.0003 & $0.1216^{*}$ \\
\hline$p$-value & 0.3573 & 0.0122 & $p$-value & 0.9964 & 0.0623 \\
\hline$\Delta \mathrm{J} 6 \mathrm{M}(-1)$ & 0.0741 & -0.1146 & $\Delta \mathrm{J} 10 \mathrm{Y}(-2)$ & 0.0251 & 0.0415 \\
\hline$p$-value & 0.3859 & 0.1720 & $p$-value & 0.7088 & 0.5230 \\
\hline & & & $\Delta \mathrm{J} 10 \mathrm{Y}(-3)$ & $-0.1274^{*}$ & 0.0189 \\
\hline & & & $p$-value & 0.0559 & 0.7695 \\
\hline & & & $\Delta \mathrm{J} 10 \mathrm{Y}(-4)$ & $-0.2200 * * *$ & $-0.1188^{*}$ \\
\hline & & & $p$-value & 0.0009 & 0.0619 \\
\hline & & & $\Delta \mathrm{J} 10 \mathrm{Y}(-5)$ & -0.0280 & -0.0174 \\
\hline & & & $p$-value & 0.6736 & 0.7868 \\
\hline & & & $\Delta \mathrm{J} 10 \mathrm{Y}(-6)$ & 0.0377 & -0.0650 \\
\hline & & & $p$-value & 0.5685 & 0.3103 \\
\hline & & & $\Delta \mathrm{J} 10 \mathrm{Y}(-7)$ & 0.0020 & 0.0234 \\
\hline & & & $p$-value & 0.9759 & 0.7111 \\
\hline & & & $\Delta \mathrm{J} 10 \mathrm{Y}(-8)$ & -0.0426 & -0.0070 \\
\hline & & & $p$-value & 0.5089 & 0.9110 \\
\hline & & & $\Delta \mathrm{J} 10 \mathrm{Y}(-9)$ & 0.0002 & $-0.1125^{*}$ \\
\hline & & & $p$-value & 0.9974 & 0.0695 \\
\hline & & & $\Delta \mathrm{J} 10 \mathrm{Y}(-10)$ & 0.0827 & -0.0230 \\
\hline & & & $p$-value & 0.1978 & 0.7108 \\
\hline & & & $\Delta \mathrm{J} 6 \mathrm{M}(-1)$ & 0.0735 & -0.0449 \\
\hline
\end{tabular}




\begin{tabular}{|c|c|c|c|c|c|}
\hline & & & $p$-value & 0.2932 & 0.5075 \\
\hline & & & $\Delta \mathrm{J} 6 \mathrm{M}(-2)$ & 0.0894 & -0.0104 \\
\hline & & & $p$-value & 0.1953 & 0.8766 \\
\hline & & & $\Delta \mathrm{J} 6 \mathrm{M}(-3)$ & 0.0693 & 0.0104 \\
\hline & & & $p$-value & 0.3122 & 0.8759 \\
\hline & & & $\Delta \mathrm{J} 6 \mathrm{M}(-4)$ & 0.0756 & $0.1306^{* *}$ \\
\hline & & & $p$-value & 0.2609 & 0.0451 \\
\hline & & & $\Delta \mathrm{J} 6 \mathrm{M}(-5)$ & -0.0797 & -0.0365 \\
\hline & & & $p$-value & 0.2376 & 0.5762 \\
\hline & & & $\Delta \mathrm{J} 6 \mathrm{M}(-6)$ & 0.0572 & 0.0998 \\
\hline & & & $p$-value & 0.3970 & 0.1271 \\
\hline & & & $\Delta \mathrm{J} 6 \mathrm{M}(-7)$ & -0.1103 & $0.1152 *$ \\
\hline & & & $p$-value & 0.1009 & 0.0768 \\
\hline & & & $\Delta \mathrm{J} 6 \mathrm{M}(-8)$ & -0.0070 & $0.1151^{*}$ \\
\hline & & & $p$-value & 0.9178 & 0.0817 \\
\hline & & & $\Delta \mathrm{J} 6 \mathrm{M}(-9)$ & 0.0165 & $0.2050 * * *$ \\
\hline & & & $p$-value & 0.8087 & 0.0020 \\
\hline & & & $\Delta \mathrm{J} 6 \mathrm{M}(-10)$ & -0.0198 & 0.0837 \\
\hline & & & $p$-value & 0.7715 & 0.2060 \\
\hline $\operatorname{Adj.} R^{2}$ & 0.0327 & 0.0103 & $\operatorname{Adj.} R^{2}$ & 0.0505 & 0.0418 \\
\hline \multicolumn{3}{|c|}{ Panel E. J10Y and J5Y } & \multicolumn{3}{|c|}{ Panel F. J10Y and J7Y } \\
\hline \multicolumn{3}{|c|}{ Cointegrating equation } & \multicolumn{3}{|c|}{ Cointegrating equation } \\
\hline & \multicolumn{2}{|l|}{ Coefficients } & & \multicolumn{2}{|l|}{ Coefficients } \\
\hline $\mathrm{J} 10 \mathrm{Y}(-1)$ & 1.0000 & & $\mathrm{~J} 10 \mathrm{Y}(-1)$ & 1.0000 & \\
\hline $\mathrm{J} 5 \mathrm{Y}(-1)$ & $-0.9141^{* * *}$ & & $\mathrm{~J} 7 \mathrm{Y}(-1)$ & $-0.9412 * * *$ & \\
\hline$p$-value & 0.0000 & & $p$-value & 0.0000 & \\
\hline Intercept & $-0.7252 * * *$ & & Intercept & $-0.4334 * * *$ & \\
\hline$p$-value & 0.0000 & & $p$-value & 0.0000 & \\
\hline \multicolumn{3}{|c|}{ Error corrections } & \multicolumn{3}{|c|}{ Error corrections } \\
\hline \multicolumn{3}{|c|}{ Variables } & & \multicolumn{2}{|l|}{ Variables } \\
\hline & $\Delta \mathrm{J} 10 \mathrm{Y}$ & $\Delta \mathrm{J} 5 \mathrm{Y}$ & & $\Delta \mathrm{J} 10 \mathrm{Y}$ & $\Delta \mathrm{J} 7 \mathrm{Y}$ \\
\hline & Coefficients & Coefficients & & Coefficients & Coefficients \\
\hline $\mathrm{CE}$ & $-0.1284 * * *$ & -0.0358 & $\mathrm{CE}$ & $-0.1289 * *$ & -0.0144 \\
\hline$p$-value & 0.0023 & 0.3965 & $p$-value & 0.0186 & 0.7917 \\
\hline$\Delta \mathrm{J} 10 \mathrm{Y}(-1)$ & 0.0148 & -0.0527 & $\Delta \mathrm{J} 10 \mathrm{Y}(-1)$ & -0.1234 & $-0.2598 * *$ \\
\hline$p$-value & 0.8815 & 0.5991 & $p$-value & 0.3120 & 0.0334 \\
\hline$\Delta \mathrm{J} 5 \mathrm{Y}(-1)$ & 0.0853 & 0.1641 & $\Delta \mathrm{J} 7 \mathrm{Y}(-1)$ & $0.2356^{*}$ & $0.3679 * * *$ \\
\hline$p$-value & 0.3954 & 0.1051 & $p$-value & 0.0564 & 0.0029 \\
\hline Adj. $R^{2}$ & 0.0259 & 0.0062 & Adj. $R^{2}$ & 0.0258 & 0.0186 \\
\hline
\end{tabular}

Notes: This table displays the estimation results of the bivariate-VECMs for the JGB yields in Japan. In this table, J6M denotes the six-month JGB yield; J1Y means the one-year JGB yield: J2Y is the two-year JGB yield; J3Y means the three-year JGB yield; J5Y denotes the five-year JGB yield; J7Y is the seven-year JGB yield; J10Y means the ten-year JGB yield. The samples are monthly and our full sample period spans January 1984 to December 2014. Moreover, CE means the cointegrating equation and $A d j . R^{2}$ denotes the adjusted $R$-squared value. Further, $* * *, * *$, and $*$ denote the statistical significance at the 1,5 , and $10 \%$ levels, respectively.

Therefore, to sum up, our VECMs effectively capture the reverting characteristics of longer-maturity JGBs' yields to the relationship between longer- and shorter-maturity JGBs' yields, which is suggested by the CEs in the VECMs. This means that the VECM is one of the most favorable models to analyze the time-series evolution and linkage as to the term structure of the JGBs in Japan. 
Panel A. CE of J1Y and J6M

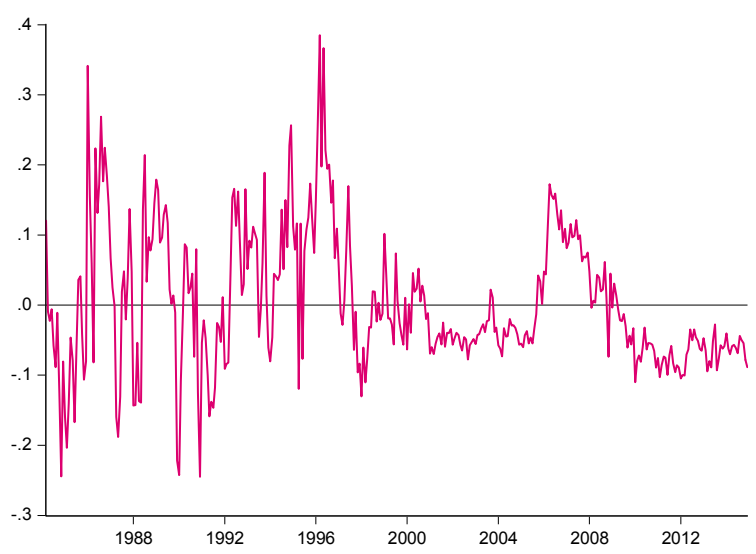

Panel C. CE of J3Y and J6M

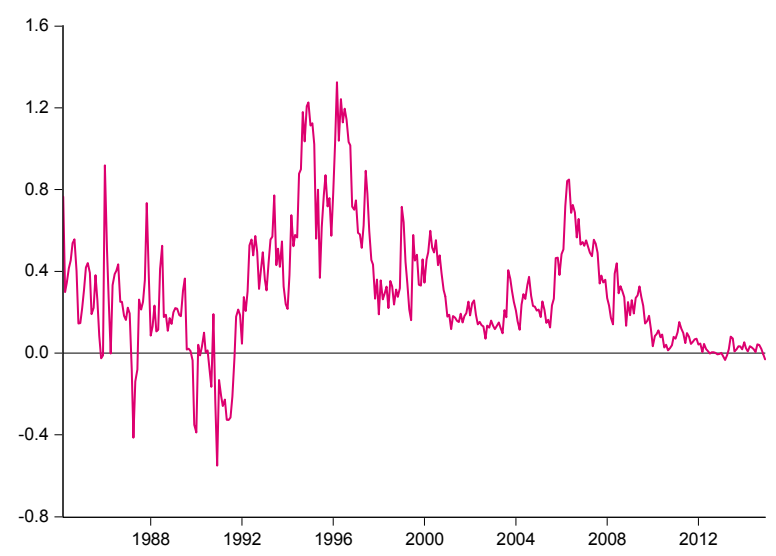

Panel E. CE of J10Y and J5Y

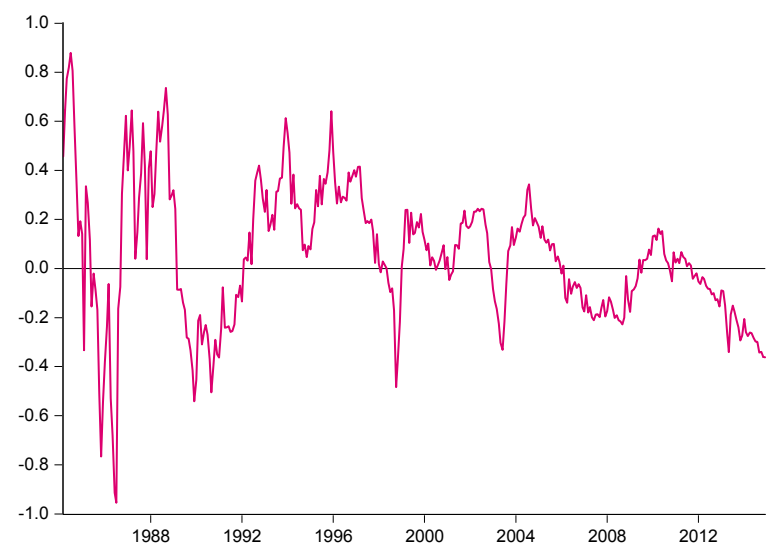

Panel B. CE of J2Y and J6M

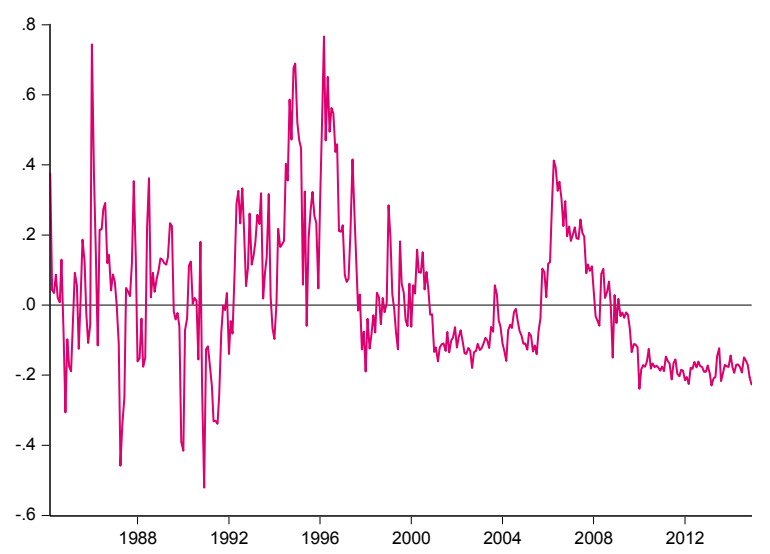

Panel D. CE of J10Y and J6M

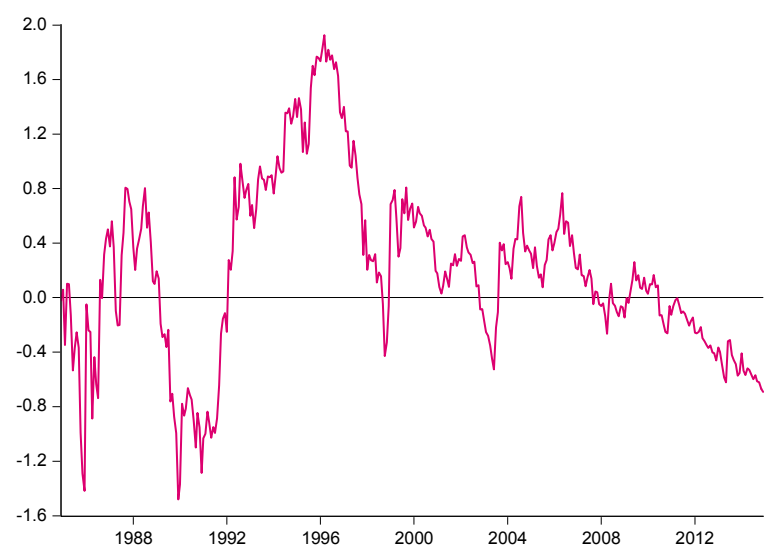

Panel F. CE of J10Y and J7Y

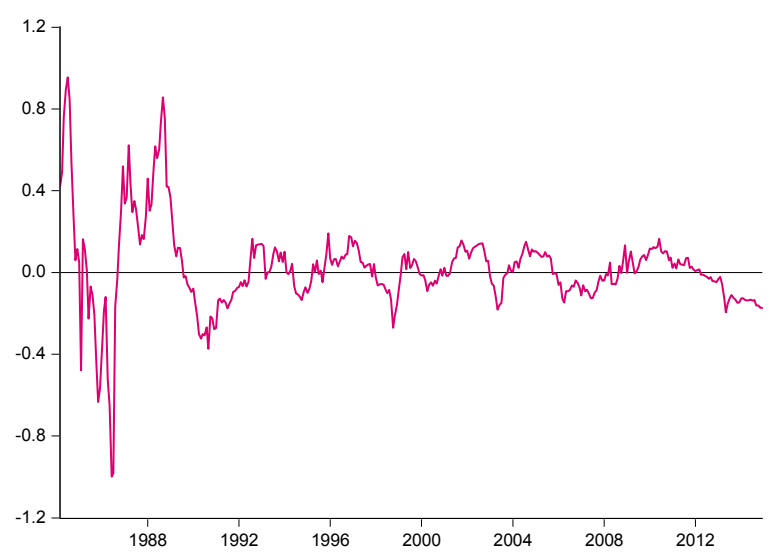

Figure 2. Time-series evolution of the cointegrating equations derived from the VECMs

\section{Summary and Conclusions}

This paper empirically approached to modeling the term structure of the JGB yields in Japan. The interesting findings derived from our investigations by applying the VECMs are as follows. 1) First, we evidenced that the relations between longer-term JGB yields and shorter-term JGB yields were effectively captured by the CEs in the VECMs. 2) Second, the CEs in the VECMs for the JGBs' term structure statistically significantly explained the time-series changes of the longer-term JGB yields in general. This evidence can be interpreted that our VECMs well captured the time-series characteristic of the longer-maturity JGBs' yields which tended to revert to the conintegrating relations between the longer- and shorter-maturity JGB yields. 
We consider that the above empirical findings are interesting and useful for the future research not only for the Japanese bond markets but also for the other international bond markets. For example, recently, the international economic environment is rapidly changing, thus analyzing the term structure by using VECMs and different multiple sample periods shall be important; it may lead to additional new empirical findings. Further, it is considered that the time-series data of the CEs derived from VECMs could be used for analyzing the evolution of macroeconomy. Moreover, similar application of VECMs with our present study could be also implemented for investigating the relations between government bond yields and corporate bond yields, for example. We consider that these possible studies are our future works and this study should be an important and useful step for various related researches in the future.

\section{Acknowledgments}

I am particularly grateful to the repeated kind invitation from the journal to write to this journal. I also appreciate the Japan Society for the Promotion of Science, the Zengin Foundation for Studies on Economics and Finance, and the Chuo University Grant for Special Research for their generous financial assistance to this research. Moreover, I thank the anonymous referees and the Editor of this journal for their very quick review and kind comments to this paper. Furthermore, I also thank Maple Xiao for the kind and very quick assistance to my paper. Finally, I deeply thank the Editors of this journal for their kindness to my paper.

\section{References}

Chadha, J. S., \& Waters, A. (2014). Applying a macro-finance yield curve to UK quantitative Easing. Journal of Banking \& Finance, 39, 68-86. http://dx.doi.org/10.1016/j.jbankfin.2013.11.008

Cox, J. C., Ingersoll, J. E., \& Ross, S. A. (1985). A theory of the term structure of interest rates. Econometrica, 53, 385-407. http://dx.doi.org/10.2307/1911242

Dang-Nguyen, S., Le Caillec, J. M., \& Hillion, A. (2014). The deterministic shift extension and the affine dynamic Nelson-Siegel model. North American Journal of Economics and Finance, 29, 402-417. http://dx.doi.org/10.1016/j.najef.2014.06.008

Hamilton, J. D., \& Wu, J. C. (2014). Testable implications of affine term structure models. Journal of Econometrics, 178, 231-242. http://dx.doi.org/10.1016/j.jeconom.2013.08.024

Heath, D., Jarrow, R., \& Morton, A. (1992). Bond pricing and the term structure of interest rates: A new methodology for contingent claims valuation. Econometrica, 60, 77-105. http://dx.doi.org/10.2307/2951677

Hull, J., \& White, A. (1990). Pricing interest-rate-derivative securities. Review of Financial Studies, 3, 573-592. http://dx.doi.org/10.1093/rfs/3.4.573

Johansen, S. (1991). Estimation and hypothesis testing of cointegration vectors in gaussian vector autoregressive models. Econometrica, 59, 1551-1580. http://dx.doi.org/ 10.2307/2938278

Johansen, S. (1995). Likelihood-based Inference in cointegrated vector autoregressive models. Oxford: Oxford University Press.

Jotikasthira, C., Le, A., \& Lundblad, C. (2015). Why do term structures in different currencies co-move? Journal of Financial Economics, 115, 58-83. http://dx.doi.org/10.1016/j.jfineco.2014.09.004

Kung, H. (2015). Macroeconomic linkages between monetary policy and the termstructure of interest rates. Journal of Financial Economics, 115, 42-57. http://dx.doi.org/10.1016/j.jfineco.2014.09.006

Nelson, C. R., \& Seigel, A. F. (1987). Parsimonious modeling of yield curves. Journal of Business, 60, 473-489.

Paccagnini, A. (2015). The macroeconomic determinants of the US term structure during the great moderation. Economic Modelling, forthcoming. http://dx.doi.org/10.1016/j.econmod.2014.11.013

Vasicek, O. (1977). An equilibrium characterization of the term structure. Journal of Financial Econometric, 5 , 177-188. http://dx.doi.org/10.1016/0304-405X(77)90016-2

\section{Copyrights}

Copyright for this article is retained by the author(s), with first publication rights granted to the journal.

This is an open-access article distributed under the terms and conditions of the Creative Commons Attribution license (http://creativecommons.org/licenses/by/3.0/). 